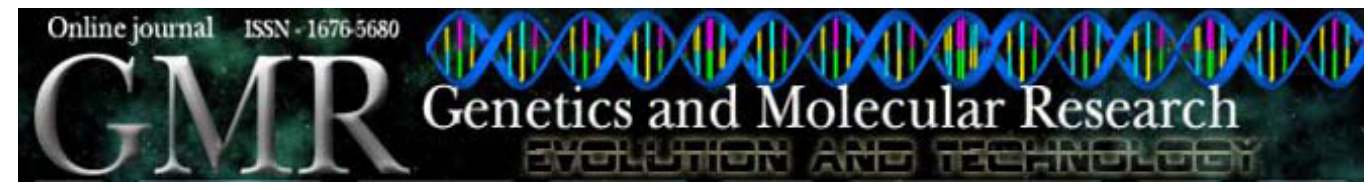

\title{
Mutation characteristics in type I collagen genes in Chinese patients with osteogenesis imperfecta
}

\author{
Z. Yang, Z.F. Ke, C. Zeng, Z. Wang, H.J. Shi and L.T. Wang \\ Department of Pathology, The First Affiliated Hospital of Sun Yat-sen University, \\ Guangzhou, P.R. China \\ Corresponding author: L.T. Wang \\ E-mail: wanglt007@yahoo.com.cn \\ Genet. Mol. Res. 10 (1): 177-185 (2011) \\ Received August 25, 2010 \\ Accepted October 22, 2010 \\ Published February 8, 2011 \\ DOI 10.4238/vol10-1gmr984
}

\begin{abstract}
Osteogenesis imperfecta is normally caused by an autosomal dominant mutation in the type I collagen genes COL1A1 and COL1A2. The severity of osteogenesis imperfecta varies, ranging from perinatal lethality to a very mild phenotype. Although there have been many reports of COL1A1 and COL1A2 mutations, few cases have been reported in Chinese people. We report on five unrelated families and three sporadic cases. The mutations were detected by PCR and direct sequencing. Four mutations in COL1A1 and one in COL1A2 were found, among which three mutations were previously unreported. The mutation rates of $\mathrm{G}>\mathrm{C}$ at base 128 in intron 31 of the COL1A1 gene and $\mathrm{G}>\mathrm{A}$ at base 162 in intron 30 of the COL1A2 gene were higher than normal. The patients' clinical characteristics with the same mutation were variable even in the same family. We conclude that mutations in COL1A1 and COL1A2 also have an important role in osteogenesis imperfecta in the Chinese population. As the Han Chinese people account for a quarter of the world's population, these new data contribute to the type I collagen mutation map.
\end{abstract}

Key words: Osteogenesis imperfecta; COL1A1; COL1A2; Heredity; Mutation 


\section{INTRODUCTION}

Osteogenesis imperfecta (OI; MIM 166210) is a heritable disease of bone characterized by brittle bones and low bone mass with other associated clinical symptoms such as short stature, dentinogenesis imperfecta, hyperlaxity of ligaments and skin, blue sclera, and hearing loss. Traditionally, four different types (I-IV) are distinguished according to the Sillence classification based on clinical phenotype and disease severity (Benusiene and Kucinskas, 2003). OI type I is a mild form of the disease, types II and III are severe subgroups, and patients with OI type IV demonstrate a moderate phenotype. Recently, two new groups of patients initially classified with OI type IV, a heterogeneous form of the disease, are shown to have unique clinical and histological features. These new OI forms have subsequently been named types V (Chessler et al., 1993), VI and VII (Engel and Prockop, 1991; Di Lullo et al., 2002). Osteogenesis imperfecta can affect all races. The expression profiles and characteristics of mutations are influenced by ethnic background. There have been several reports about COL1A1 and COL1A2 mutations in Lithuanian, Finnish, American, Israeli, and Canadian populations (Forlino and Marini, 2000; Glorieux et al., 2000; Hartikka et al., 2004), but they have been restricted to western populations and only a few cases have been reported from Asia, especially in Chinese people.

In this study, we analyzed the COL1A1 gene, which encodes $\alpha 1$ (I) chains of type I collagen, and COL1A2 gene, which encodes $\alpha 2$ (I) chains of type I collagen, in five unrelated Chinese families and three sporadic cases with OI.

\section{MATERIAL AND METHODS}

\section{Patients}

The protocol for the study was approved by the Ethics Committee in the First Affiliated Hospital of Sun Yat-sen University. Informed consent was obtained from all members participating in this study. Five unrelated families and three sporadic cases came from Han Chinese people (almost 92\% of Chinese people). Patients' unaffected parents were also studied in some instances to ascertain the presence of novel sequence changes. None of the sequence changes reported here was detected in 50 normal control chromosomes. Each family contained a proband and their parents. According to the Sillence classification, four patients were clinically diagnosed as OI type I, three were type III and one was type IV.

\section{Mutational analysis}

DNA was obtained from blood samples of the probands, their parents and 50 unrelated healthy people, using TianGen DNA Mini Kits according to the manufacturer protocol. COL1A1 and COL1A2 were chosen as the target gene. The primers were designed by the Primer Premier 5.0 software. The amplifications covered the promoter, the entire coding region and intron-exon boundaries (Table 1, Table 2). Polymerase chain reaction (PCR) amplification was performed in a $50 \mu \mathrm{L}$ final volume, with $0.8 \mu \mathrm{g}$ DNA template, $4 \mu \mathrm{L}(10 \mathrm{mM})$ of each of the primers, $24 \mu \mathrm{L} 2 \mathrm{X}$ Taq Platinum PCR MasterMix (TIANGEN BOITECH, Beijing, P.R. China). The amplified products were electrophoresed through a $1.5 \%$ agarose gel. 


\begin{tabular}{|c|c|c|c|c|}
\hline No. & Primer sequence & Length (bp) & Exon & $\mathrm{Tm}$ \\
\hline \multirow[t]{2}{*}{1} & 1-1: 5' GGAGCAGACGGGAGTTTC 3' & 349 & Exon 1 & $55^{\circ} \mathrm{C}$ \\
\hline & 1-2: 5' TCATCATCTCCСТTCCATTCC 3' & & & \\
\hline \multirow[t]{2}{*}{2} & 2-1: 5' TTGAGGAAAGAAGAACGGG 3' & 1000 & Exon 2-5 & $57^{\circ} \mathrm{C}$ \\
\hline & 2-2: 5' AAACTGTGAAGGGTATGTGAGA 3' & & & \\
\hline \multirow[t]{2}{*}{3} & 3-1: 5' GCCGTCTTCTGCCTTTCA 3' & 524 & Exon 6-7 & $55^{\circ} \mathrm{C}$ \\
\hline & 3-2: 5' GTCCCTGTCAACCTTCTCCAAT 3' & & & \\
\hline \multirow[t]{2}{*}{4} & 4-1: 5' GGAAGACTGGGATGAGGG 3' & 460 & Exon 8-9 & $57^{\circ} \mathrm{C}$ \\
\hline & 4-2: 5' CAAATGTGGTGGAGTGGA 3' & & & \\
\hline \multirow[t]{2}{*}{5} & 5-1: 5' GAGGCACTCAGATTTCACC 3' & 492 & Exon $10-11$ & $57^{\circ} \mathrm{C}$ \\
\hline & 5-2: 5' CTTTTGGGGAAGAGGTTG 3' & & & \\
\hline \multirow[t]{2}{*}{6} & 6-1: 5' GGAAAGCAGTCCCGATTA 3' & 784 & Exon $12-15$ & $57^{\circ} \mathrm{C}$ \\
\hline & 6-2: 5' AACATAACCTGCTCCCATT 3' & & & \\
\hline \multirow[t]{2}{*}{7} & 7-1: 5' CCATCTCTTCCTTCTCGC 3' & 522 & Exon $16-17$ & $57^{\circ} \mathrm{C}$ \\
\hline & 7-2: 5' GAGTGTCAGCAACAGGCA 3' & & & \\
\hline \multirow[t]{2}{*}{8} & 8-1: 5' CCTTTGCCACTTTCTAACCT 3' & 602 & Exon $18-20$ & $57^{\circ} \mathrm{C}$ \\
\hline & 8-2: 5' GGACTCCCCCAGAAGACTA 3' & & & \\
\hline \multirow[t]{2}{*}{9} & 9-1: 5' CAGAAAGGAAGAGGAGCC 3' & 704 & Exon 21-23 & $57^{\circ} \mathrm{C}$ \\
\hline & 9-2: 5' GAACGCCTCATCCCAGAC 3' & & & \\
\hline \multirow[t]{2}{*}{10} & 10-1: 5' CTGGGATGAGGCGTTCTG 3' & 515 & Exon $24-25$ & $57^{\circ} \mathrm{C}$ \\
\hline & 10-2: 5' CGCCGAGAAGTCTTTCATTT 3' & & & \\
\hline \multirow[t]{2}{*}{11} & 11-1: 5' GCCCTGGCTTCTCACTTC 3' & 738 & Exon 26-29 & $57^{\circ} \mathrm{C}$ \\
\hline & 11-2: 5' CGGCGTCTAACCTCAATC 3' & & & \\
\hline \multirow[t]{2}{*}{12} & 12-1: 5' CCAGACCCCAGGAGGAAG 3' & 799 & Exon $30-32$ & $60^{\circ} \mathrm{C}$ \\
\hline & 12-2: 5' GAGAGATTCAAAGCAGGCAGA 3' & & & \\
\hline \multirow[t]{2}{*}{13} & 13-1: 5' GAAACCCAGACACAAGCAGA 3' & 750 & Exon 33-36 & $53^{\circ} \mathrm{C}$ \\
\hline & 13-2: 5' TTGTCCTCATTCCGTCCC 3' & & & \\
\hline \multirow[t]{2}{*}{14} & 14-1: 5' GTTTCCCACCCAAGCATCT 3' & 441 & Exon $37-38$ & $54^{\circ} \mathrm{C}$ \\
\hline & 14-2: 5' AGCCAACTCATCCGACCC 3' & & & \\
\hline \multirow[t]{2}{*}{15} & 15-1: 5' GCTGGGTCGGATGAGTTG 3' & 505 & Exon $39-40$ & $57^{\circ} \mathrm{C}$ \\
\hline & 15-2: 5' AAACAGGGGTGAGGTGCC 3' & & & \\
\hline \multirow[t]{2}{*}{16} & 16-1: 5' TGCTGATGGTCCTGCTGTA 3' & 561 & Exon $41-42$ & $57^{\circ} \mathrm{C}$ \\
\hline & 16-2: 5' GGGAAGAGGGCTTAGGCA 3' & & & \\
\hline \multirow[t]{2}{*}{17} & 17-1: 5' GCCTTGCCTAAGCCCTCT 3' & 412 & Exon $43-44$ & $58^{\circ} \mathrm{C}$ \\
\hline & 17-2: 5' AAGTCCGACACCCATCCC 3' & & & \\
\hline \multirow[t]{2}{*}{18} & 18-1: 5' GGGAGTTGGGAGAGATGGC 3' & 481 & Exon $45-46$ & $61^{\circ} \mathrm{C}$ \\
\hline & 18-2: 5' GGGAAACTGAGGCGAAGC 3' & & & \\
\hline \multirow[t]{2}{*}{19} & 19-1: 5' ACATTTGACGCTCACTGGG 3' & 626 & Exon $47-48$ & $62^{\circ} \mathrm{C}$ \\
\hline & 19-2: 5' CAAGTGCTTTGGGGGCTG 3' & & & \\
\hline \multirow[t]{2}{*}{20} & 20-1: 5' CTCATCCCCTCTGCTCAT 3' & 794 & Exon $49-50$ & $57^{\circ} \mathrm{C}$ \\
\hline & 20-2: 5' GCTCTGTCCATCACCCTTA 3' & & & \\
\hline \multirow[t]{2}{*}{21} & 21-1: 5' TAGTGGTTCAGACACAGGC 3' & 749 & Exon 51-52 & $58^{\circ} \mathrm{C}$ \\
\hline & 21-2: 5' GGTTGCTTGTCTGTTTCC 3' & & & \\
\hline \multirow[t]{2}{*}{22} & 22-1: 5' CCACCCAACCAACTTTCC 3' & 770 & Exon 52 & $57^{\circ} \mathrm{C}$ \\
\hline & 22-2: 5' AACGAGGTAGTCTTTCAGCA 3' & & & \\
\hline \multirow[t]{2}{*}{23} & 23-1: 5' CACTGGGTTCGGAGGAGA 3' & 857 & Exon 52 & $57^{\circ} \mathrm{C}$ \\
\hline & 23-2: 5' AAAGGGCAGGAATGGAAG 3' & & & \\
\hline
\end{tabular}

$\mathrm{Tm}=$ melting temperature.

DNA sequencing of PCR-amplified COL1A1 and COL1A2 gene fragments was carried out using an ABI 3730 automated sequencer and the Big Dye Terminator Sequencing protocol. Fifty normal chromosomes were similarly analyzed at the same time. All mutations were verified for accuracy of nucleotide composition of codons and exonintron junctions and their location within the gene, using the GenBank sequences of COL1A1 (NC_00001 for genomic) and COL1A2 (NC_007405). The product was then compared and analyzed using BLAST, DNAStar and Primer Premier 5.0 softwares. 


\begin{tabular}{|c|c|c|c|c|}
\hline No. & Primer sequence & Length (bp) & Exon & $\mathrm{Tm}$ \\
\hline \multirow[t]{2}{*}{1} & 1-1: 5' CCTTATTATTTTAGCACCACGGC 3' & & & \\
\hline & 1-2: 5' CAGGTTACAGGTTTTCCTTTTCAG 3' & 309 & Exon 1 & $59^{\circ} \mathrm{C}$ \\
\hline \multirow[t]{2}{*}{2} & 2-1: 5' CCCTGCCATACTTTTGACCTG 3' & & & \\
\hline & 2-2: 5' TTATTAGCCCCGCCTATTTTG 3' & 365 & Exon 2 & $55^{\circ} \mathrm{C}$ \\
\hline \multirow[t]{2}{*}{3} & 3-1: 5' GCGAATCTTTTCACTCCTTTG 3' & & & \\
\hline & 3-2: 5' GCGAATCACCAGTTTGTATCA 3' & 557 & Exon 3 & $53^{\circ} \mathrm{C}$ \\
\hline \multirow[t]{2}{*}{4} & 4-1: 5' TTATTCTGGAGATGGAAGGCA 3' & & & \\
\hline & 4-2: 5' CGAGGACTGTGGTGGTAGGTA 3' & 742 & Exon 4 & $54^{\circ} \mathrm{C}$ \\
\hline \multirow[t]{2}{*}{5} & 5-1: 5' GGATACGATGTAAGTCCTTGTGC 3' & & & \\
\hline & 5-2: 5' GGGTAAAGCAGAATCTTGAGTGA 3' & 594 & Exon 5 & $54^{\circ} \mathrm{C}$ \\
\hline \multirow[t]{2}{*}{6} & 6-1: 5' GGTAAAAGGTGGGAGTGGA 3' & & & \\
\hline & 6-2: 5' GGTATGCCTCTAAGTGTTGCT 3' & 749 & Exon 6 & $54^{\circ} \mathrm{C}$ \\
\hline \multirow[t]{2}{*}{7} & 7-1: 5' GAACCTATCTGCCCCGTCTAA 3' & & & \\
\hline & 7-2: 5' CGCCTTCTTCTTGGTAAACTATC 3' & 858 & Exon $7-9$ & $54^{\circ} \mathrm{C}$ \\
\hline \multirow[t]{2}{*}{8} & 8-1: 5' GCGATAACTTTCTCCCCTTGC 3' & & & \\
\hline & 8-2: 5' CGATGATTTTCAGACGGTTGT 3' & 899 & Exon $10-11$ & $51^{\circ} \mathrm{C}$ \\
\hline \multirow[t]{2}{*}{9} & 9-1: 5' TGCCAAAGGGAAGAAAGAGTT 3' & & & \\
\hline & 9-2: 5' GCGGAATAATAGAGGGAGGAA 3' & 746 & Exon 12 & $52^{\circ} \mathrm{C}$ \\
\hline \multirow[t]{2}{*}{10} & 10-1: 5' GCCACTCAAATAACCACATCT 3' & & & \\
\hline & 10-2: 5' GCCGTGCTATTTCGTAAGAG 3' & 861 & Exon $13-15$ & $52^{\circ} \mathrm{C}$ \\
\hline \multirow[t]{2}{*}{11} & 11-1: 5' AGTTGAGAATGTGGGGTGGGT 3' & & & \\
\hline & 11-2: 5' GGGGTTTCCTATTTTCCTTGC 3' & 765 & Exon 16 & $56^{\circ} \mathrm{C}$ \\
\hline \multirow[t]{2}{*}{12} & 12-1: 5' GGAGACAGAAGGAGAGGGAAGGT 3' & & & \\
\hline & 12-2: 5' GGGCTAAAAATGCTAAGGAAGAGA 3' & 845 & Exon 17-19 & $57^{\circ} \mathrm{C}$ \\
\hline \multirow[t]{2}{*}{13} & 13-1: 5' GGAATACCACCTCTGCCATCAT 3' & & & \\
\hline & 13-2: 5' TCAAGACACAAACCAAGCCAAA 3' & 937 & Exon $20-21$ & $56^{\circ} \mathrm{C}$ \\
\hline 14 & 14-1: 5' CGTCTGTATCTCCCCTGTAA 3' & & & \\
\hline & 14-2: 5' GGAACCTCATAGCCATTGTA 3' & 595 & Exon $22-23$ & $50^{\circ} \mathrm{C}$ \\
\hline 15 & 15-1: 5' GGGGCAGAACTCTTTTCACACT 3' & & & \\
\hline & 15-2: 5' CGATGGATTTTTAGCAGGGATA 3' & 977 & Exon 24-25 & $54^{\circ} \mathrm{C}$ \\
\hline 16 & 16-1: 5' ATCCCTGCTAAAAATCCATCTC 3' & & & \\
\hline & 16-2: 5' GGGGTAAAATAAAAGCCAAGTG 3' & 523 & Exon 26 & $55^{\circ} \mathrm{C}$ \\
\hline 17 & 17-1: 5' AGTATTTGGGCTTTCGTGG 3' & & & \\
\hline & 17-2: 5' GTGGGGTAGTAAACAGGGG 3' & 802 & Exon 27-29 & $51^{\circ} \mathrm{C}$ \\
\hline 18 & 18-1: 5' GCCAAGTTCTGGGATGGATAC 3' & & & \\
\hline & 18-2: 5' CGGCTTTAGGCTTTGAACATC 3' & 634 & Exon 30 & $55^{\circ} \mathrm{C}$ \\
\hline 19 & 19-1: 5' CCCCCGAATACTACACATAAC 3' & & & \\
\hline & 19-2: 5' CCCCACAGTTTGTTGCTAT 3' & 644 & Exon 31 & $52^{\circ} \mathrm{C}$ \\
\hline 20 & 20-1: 5' АСТСССАСТАСССТСАТСТСТT 3' & & & \\
\hline & 20-2: 5' CCCCCAATAAAGTGTGTGTAGT 3' & 1143 & Exon 32-33 & $55^{\circ} \mathrm{C}$ \\
\hline 21 & 21-1: 5' TTTCGGACCTGCTATGACTTACAC 3' & & & \\
\hline & 21-2: 5' GCGTCAGTGCATTAGGATATTGTT 3' & 557 & Exon 34 & $57^{\circ} \mathrm{C}$ \\
\hline 22 & 22-1: 5' CATACGATGTCCTCCTCCTGGT 3' & & & \\
\hline & 22-2: 5' GGGCAAATGTTAATCCTTCCG 3' & 812 & Exon $35-37$ & $56^{\circ} \mathrm{C}$ \\
\hline 23 & 23-1: 5' CGGTGGAAAATAACGGAAGGAT 3' & & & \\
\hline & 23-2: 5' ATAGTCAGGCAGAAGAAGGGGC 3' & 609 & Exon 38 & $58^{\circ} \mathrm{C}$ \\
\hline 24 & 24-1: 5' ACTCAGCCAGGTGGTAAAGAT 3' & & & \\
\hline & 24-2: 5' GCCCGATAACTTGTGATGAA 3' & 553 & Exon 39 & $52^{\circ} \mathrm{C}$ \\
\hline 25 & 25-1: 5' CCCTTCTACATAGTTCTGATTCCA 3' & & & \\
\hline & 25-2: 5' TCAGCAATGGGACTCTGTTCTA 3' & 759 & Exon 40 & $54^{\circ} \mathrm{C}$ \\
\hline 26 & 26-1: 5' GCGAGGATGAATCAGATACAAAAGT 3' & & & \\
\hline & 26-2: 5' AGTGCGTGGAAAGAACCAAAAA 3' & 554 & Exon 41 & $53^{\circ} \mathrm{C}$ \\
\hline 27 & 27-1: 5' CCTGGGATACTGAATGACACGA 3' & & & \\
\hline & 27-2: 5' GGGATAAAAACCTGCCAACCTA 3' & 617 & Exon 42 & $54^{\circ} \mathrm{C}$ \\
\hline 28 & 28-1: 5' CGGCTCCATAGTATCTACACCT 3' & & & \\
\hline & 28-2: 5' TGCTGGTAATCTGCTTTAGTTG 3' & 955 & Exon $43-45$ & $53^{\circ} \mathrm{C}$ \\
\hline 29 & 29-1: 5' CCCACTAAAGCAGATTACCAGCT 3' & & & \\
\hline & 29-2: 5' CCGAAATAGCATTACCTCCAAG 3' & 425 & Exon 46 & $54^{\circ} \mathrm{C}$ \\
\hline 30 & 30-1: 5' CGGGCATAATGGGAGAAAAGAG 3' & & & \\
\hline & 30-2: 5' CGGGGGTAATCAAGTTCACATAAA 3' & 665 & Exon $47-48$ & $59^{\circ} \mathrm{C}$ \\
\hline 31 & 31-1: 5' TCGCCCCATTTCAATATATCCTC 3' & & & \\
\hline & 31-2: 5' CCCGCTTTTTCAATGATTACCA 3' & 1327 & Exon $49-50$ & $59^{\circ} \mathrm{C}$ \\
\hline 32 & 32-1: 5' CCCCGATAACTTTTTTAGATGACC 3' & & & \\
\hline & 32-2: 5' CCTGGGCACACATTACCATTTA 3' & 795 & Exon 51 & $58^{\circ} \mathrm{C}$ \\
\hline 33 & 33-1: 5' GGCAAGACTACATACCCACCCA 3' & & & \\
\hline & 33-2: 5' GCCCACATTTTCCATAACAGGT 3' & 755 & Exon 52 & $56^{\circ} \mathrm{C}$ \\
\hline
\end{tabular}

$\mathrm{Tm}=$ melting temperature. 


\section{RESULTS}

\section{Data collected from family members}

Multiple fractures, skeletal deformity and blue sclera were found in about $87.5 \%$ (7/8) of patients; 50\% (4/8) have familial inheritance. Dentinogenesis imperfecta was found in $37.5 \%(3 / 8)$, and $12.5 \%(1 / 8)$ have intrauterine or birth fracture syndromes. The types cover type I to IV (Table 3). According to the Sillence classification, 4 patients were clinically diagnosed as OI type I, 3 as type III, and 1 as type II (Table 3 ).

\begin{tabular}{|c|c|c|c|c|c|c|c|c|}
\hline Proband & A & $\mathrm{B}$ & $\mathrm{C}$ & $\mathrm{D}$ & $\mathrm{E}$ & $\mathrm{F}$ & G & $\mathrm{H}$ \\
\hline Age (years) & 31 & 42 & 35 & 24 & 29 & 3 & 2 & 9 \\
\hline No. of fractures & 5 & 3 & 2 & $*$ & 2 & 3 & 5 & 4 \\
\hline Skeletal deformity & - & - & - & + & - & + & + & + \\
\hline Blue sclera & + & + & + & $*$ & + & + & + & + \\
\hline Dentinogenesis imperfecta & - & + & - & $*$ & + & - & + & - \\
\hline Acouesthesia damage & + & - & - & $*$ & - & - & - & - \\
\hline Family history & + & + & + & - & + & - & - & - \\
\hline Fracture at birth & - & - & - & $*$ & - & - & + & - \\
\hline Type & I & $\mathrm{I}$ & I & II & I & III & III & III \\
\hline
\end{tabular}

*Represents the characteristics, which could not be obtained because of death.

Table 4. Results of sequencing.
\begin{tabular}{llllll}
\hline Family No. & Mutant gene & Mutant location & Mutant style & & \\
\hline B & COL1A1 & Exon 1 & GAC $>$ AAC c.97G $>$ A & p.Asp33Asn & New \\
A, E & COL1A2 & Exon 3 & ACT $>$ ACC c.87T $>$ C & p.Thr29Thr & Old \\
C & COL1A1 & Exon 19 & CCT $>$ CCA c. 1209T $>$ A & p.Pro403Pro & New \\
D & COL1A1 & Exon 48 & ACC $>$ ACT c.3702C $>$ T & p.Thr1234Thr & New \\
\hline
\end{tabular}

\section{Direct sequencing}

Eight probands were diagnosed as OI. The types covered from I to III. Family history was found in 5 families and 3 were sporadic cases. Three of the patients had the mutation in the COL1A1 gene while two had the mutation in COL1A2. The mutation type in 5 families was a glycine substitution: 3 were samesense mutations: c. $87 \mathrm{~T}>\mathrm{C}$ (p.Thr29Thr); c.1209T > A (p.Pro403Pro); c.3702C > T (p.Thr1234Thr). A missense mutation was found in one site: c.97G > A (p.Asp33Asn) (Table 4). Of 50 normal chromosomes, none of the mutations described above was observed (Figure 1).

The position of the mutations refers to cDNA and protein sequences as they appear in GenBank sequence for human mRNA for preproa1, $\alpha 2$ (I) collagen (GenBank accession No. NC_00001 for COL1A1 and number NC_007405 for COL1A2 genomic). Nucleotide changes at the genomic DNA level were numbered from the first base of the transcript. Amino acid changes were numbered from the first glycine of the triple helix. 

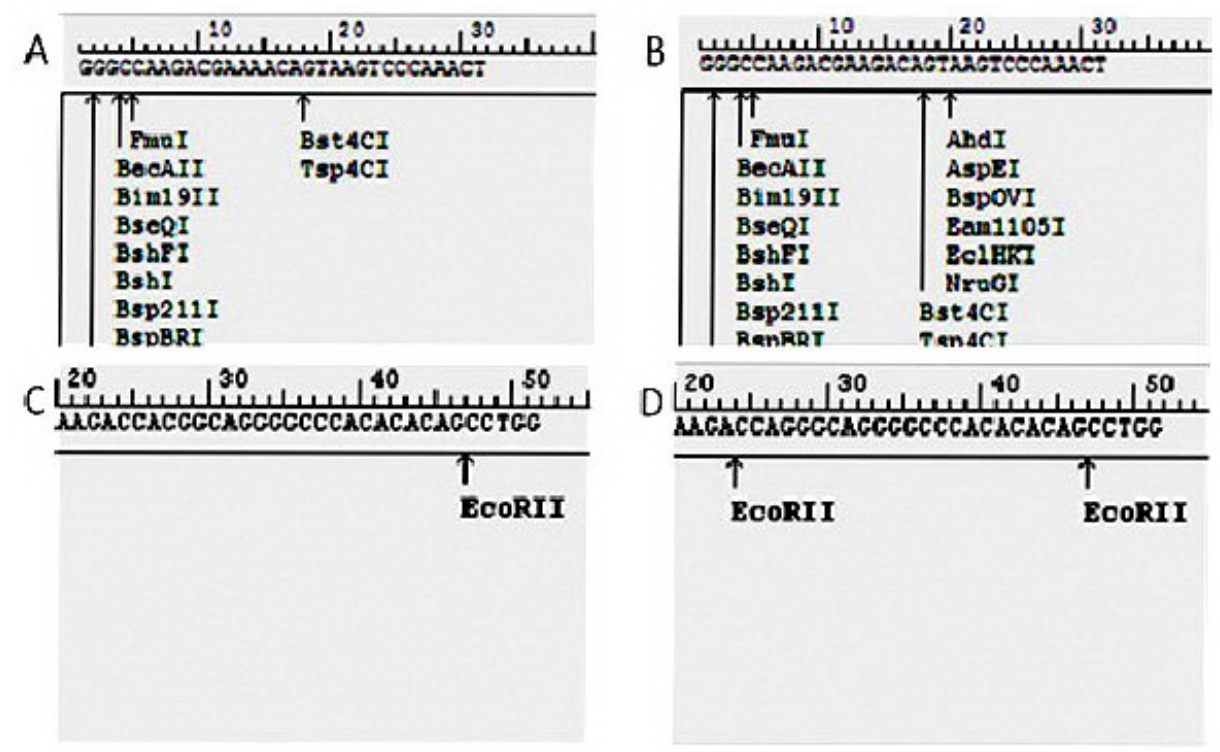

Figure 1. Computer-assisted restriction enzyme analysis with the Primer Premier 5.0 software. A shows that the mutation made the $A h d \mathrm{I}, A s p \mathrm{EI}, B s p \mathrm{OVI}, E a m 1105 \mathrm{I}, E c l \mathrm{HKI}$, and NruGI restriction enzyme sites disappear. B was the control. C shows that the mutation made the EcoRII restriction enzyme site at 124-125 basyl in intron 31 of the COL1A1 gene disappear. D was the control.

\section{Computer-assisted restriction enzyme analysis}

In the C family, AhdI, AspEI, BspOVI, Eam1105I, EclHKI, and NruGI restriction enzyme sites disappeared (Figure 1A, B).

Comparing the exon and intron of the COL1A1 and COL1A2 genes with the DNAStar software, we found that the mutation rate of $\mathrm{G}>\mathrm{C}$ at 128 basyl in intron 31 of COL1A1 gene was 33.3\% (5/15) higher than the normal (20\%, 10/50) (Figure 2A). Restriction enzyme analysis found that the EcoRII restriction enzyme site disappeared by using Primer Premier 5.0 (Figure $1 \mathrm{C}, \mathrm{D})$. The mutation rate of $\mathrm{G}>\mathrm{A}$ at 162 basyl in intron 30 of the COL1A2 gene was $53.3 \%$ $(8 / 15)$ higher than the normal ( $\sim 0 \%)$ (Figure $2 \mathrm{~B})$.

\section{DISCUSSION}

At least $95 \%$ of the cases with OI are caused by dominant mutations in the genes encoding the $\alpha 1$ (I) and $\alpha 2$ (I) subunits of collagen I (Sykes, 1993). Type I collagen is the major organic component of bone. It is a heterotrimer composed of two $\alpha 1$ (I) chains and one $\alpha 2$ (I) chain, which are encoded by the unlinked loci COL1A1 and COL1A2, respectively. COL1A1 is $18 \mathrm{~kb}$ in size and is located at $17 \mathrm{q} 21.3-\mathrm{q} 22$. COL1A2 is $38 \mathrm{~kb}$ and is located at $7 \mathrm{q} 21.3-$ q22.1 (Vuorio and de Crombrugghe, 1990; Venturi et al., 2006). The two genes are similar in structure: COL1A1 and COL1A2 have 51 and 52 exons, respectively. To date, there are few reports about the COL1A1 gene mutation in Chinese people. In our study, 5 OI families and 3 OI sporadic cases were analyzed. Four coding region mutations were found, one of which 
was in the COL1A2 gene and the other three were in the COL1A1 gene (Figure 3). Our study indicated a higher probability of gene mutation in COL1A1 $(37.5 \%, 3 / 8)$, similar to other studies (Pace et al., 2002; Benusiene and Kucinskas, 2003). The mutations described in this report will be added to the existing database of COL1A1/COL1A2 mutations associated with an OI phenotype (Type I Collagen Mutation Database: http://www.le.ac.uk/genetics/collagen/index. html and Human Gene Mutation Database: http://www.hgmd.cf.ac.uk/ac/index.php).

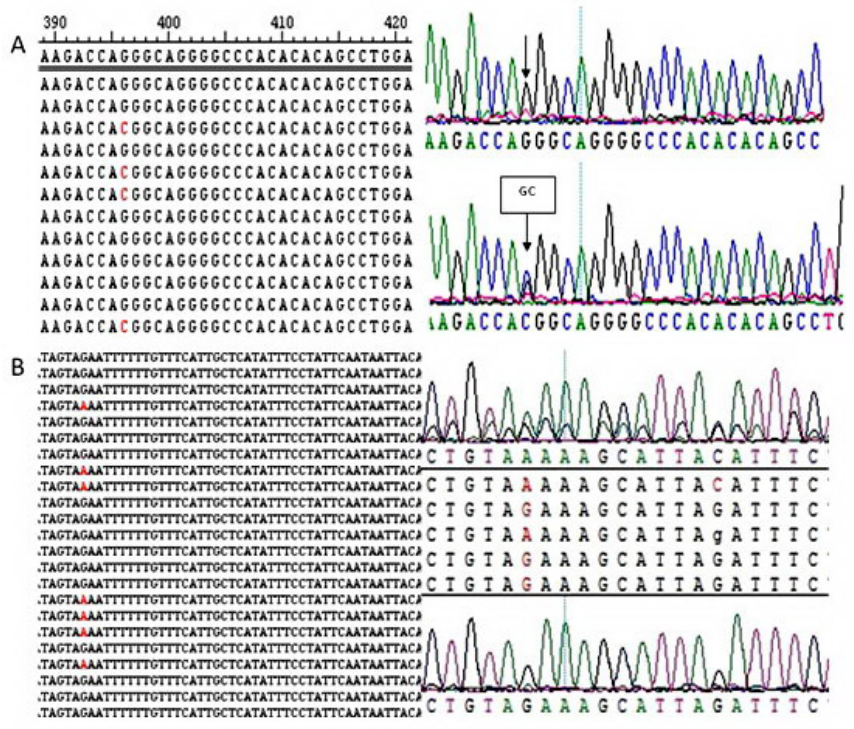

Figure 2. Comparing the exon and intron of the COL1A1 and COL1A2 genes with the DNAStar software. A. The mutation rate of $\mathrm{G}>\mathrm{C}$ at 128 basyl in intron 31 of the COL1A1 gene was $33.3 \%(5 / 15)$, which was higher than the normal 20\% (10/50). Red denotes the $\mathrm{G}>\mathrm{C}$ mutation. B. The mutation rate of $\mathrm{G}>\mathrm{A}$ at 162 basyl in intron 30 of the COL1A2 gene was $53.3 \%(8 / 15)$, which was higher than the normal $(\sim 0 \%)$. Red denotes the $\mathrm{G}>\mathrm{A}$ mutation.

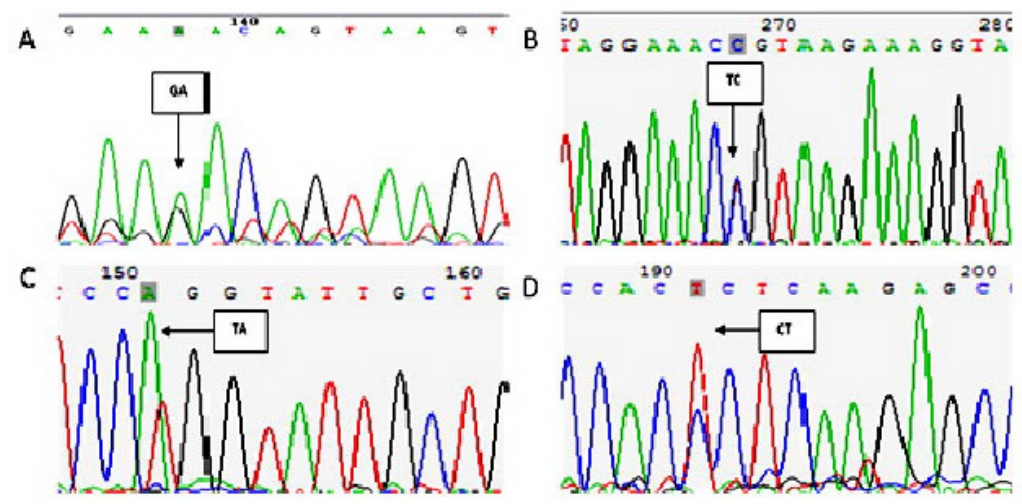

Figure 3. Four mutations were found. A. Proband of family B c.97G $>$ A mutation in exon 1 in the COL1A1 gene. B. Proband of family A,E c.87T > C mutation in exon 3 in the COL1A1 gene. C. Proband of family C c.1209T > A mutation in exon 19 in the COL1A1 gene. D. Proband of family D c.3702C > T mutation in exon 48 in the COL1A1 gene. 
If an amino acid is replaced by other types of amino acids, significantly altering particular physical, chemical and structural properties, collagen stability could be affected. The same mutation appearing in different positions can lead to different clinical manifestations. The acidic amino acid aspartate was replaced by polar neutral amino acids-asparagines in exon 1 in the proband of the B family. Currently, only one case with aspartic acid (Asp) mutations to asparagine (Asn) was reported. Pollitt et al. (2006) reported one case in 51 exon 1, but the clinical manifestations pointed to type II, the most serious type. However, the proband in B family belonged to type I, which is a relatively mild phenotype. Considering the reasons for the type I collagen triple helix folding delay, post-translation mutations, protein $\mathrm{N}$ terminal lysine hydroxylation, and glycosylation increase, the closer the mutation was to the $\mathrm{C}$ terminal mutations, the more obvious the phenotypic changes (Pepin et al., 1997).

Alterations in splice sites may lead to exon skipping, intronic inclusion, or activation of cryptic sites in introns or exons (Kuivaniemi et al., 1997). Our results from computerassisted restriction enzyme analysis found that the mutation could change the splice site at the junction between exon 1 and intron 1. Part of intron 1 could be involved in the process of translation, thus changing the protein. The 128 base mutation could make the EcoRII restriction enzyme site disappear at the 124-125 base in intron 31, which could change some regulating functions of intron 31 .

An intron has diverse functional characteristics. Furthermore, more and more studies have found that the intron has some relationships with gene transcription and control (Mattick, 1994; Bhattacharyya and Banerjee, 1999; Clement and Wilkinson, 2000). Comparing the exon and intron of the COL1A1 and COL1A2 genes with the DNAStar software, we found that the mutation rate of $\mathrm{G}>\mathrm{C}$ at 128 basyl in intron 31 of the COL1A1 gene was $33.3 \%(5 / 15)$ higher than the normal $(20 \% ; 10 / 50)$. Restriction enzyme analysis with Primer Premier 5.0 showed that the HaeIII restriction enzyme site disappeared. The mutation rate of $\mathrm{G}>\mathrm{A}$ at 162 basyl in intron 30 of the COL1A2 gene was $53.3 \%(8 / 15)$ higher than the normal $(\sim 0 \%)$. This might correlate with the OI clinical heterogeneity. But this conclusion needs to be deeply verified through more cases.

Alteration of type I procollagen posttranslational processing, in the absence of mutations in type I collagen genes, can also cause OI (Barnes et al., 2006; Morello et al., 2006). Mutations in the CRTAP and LEPRE1 genes can each have a relatively broad range of clinical presentation, from a very severe and often lethal phenotype in OI types II/III to a milder OI type VII seen with mutations in CRTAP that lead to production of some normal protein (Morello et al., 2006). In our study, there were still 3 OI probands who did not present mutation in either the COL1A1 or COL1A2 gene. We speculated that the mutation might be in the CRTAP and LEPRE1 genes.

In conclusion, osteogenesis imperfecta is an autosomal dominant inheritance disease mainly caused by the type I collagen gene mutation. Even though many mutations have been found already, the mutation hot spots have still not been found and few cases have been reported on Chinese people. As the Han Chinese people account for a quarter of the world's population, we believe that our new data can contribute to the type I collagen mutation map that is far from saturation.

\section{ACKNOWLEDGMENTS}

Research supported by the National Natural Science Foundation of China (\#30900650/ H1615), and the Foundation of Guangdong Province Natural Science (\#9451008901002146). 


\section{REFERENCES}

Barnes AM, Chang W, Morello R, Cabral WA, et al. (2006). Deficiency of cartilage-associated protein in recessive lethal osteogenesis imperfecta. N. Engl. J. Med. 355: 2757-2764.

Benusiene E and Kucinskas V (2003). COL1A1 mutation analysis in Lithuanian patients with osteogenesis imperfecta. $J$. Appl. Genet. 44: 95-102.

Bhattacharyya N and Banerjee D (1999). Transcriptional regulatory sequences within the first intron of the chicken apolipoprotein AI (apoAI) gene. Gene 234: 371-380.

Chessler SD, Wallis GA and Byers PH (1993). Mutations in the carboxyl-terminal propeptide of the pro alpha 1(I) chain of type I collagen result in defective chain association and produce lethal osteogenesis imperfecta. J. Biol. Chem. 268: $18218-18225$.

Clement JQ and Wilkinson MF (2000). Rapid induction of nuclear transcripts and inhibition of intron decay in response to the polymerase II inhibitor DRB. J. Mol. Biol. 299: 1179-1191.

Di Lullo GA, Sweeney SM, Korkko J, Ala-Kokko L, et al. (2002). Mapping the ligand-binding sites and disease-associated mutations on the most abundant protein in the human, type I collagen. J. Biol. Chem. 277: 4223-4231.

Engel J and Prockop DJ (1991). The zipper-like folding of collagen triple helices and the effects of mutations that disrupt the zipper. Annu. Rev. Biophys. Biophys. Chem. 20: 137-152.

Forlino A and Marini JC (2000). Osteogenesis imperfecta: prospects for molecular therapeutics. Mol. Genet. Metab. 71: 225-232.

Glorieux FH, Rauch F, Plotkin H, Ward L, et al. (2000). Type V osteogenesis imperfecta: a new form of brittle bone disease. J. Bone Miner. Res. 15: 1650-1658.

Hartikka H, Kuurila K, Korkko J, Kaitila I, et al. (2004). Lack of correlation between the type of COL1A1 or COL1A2 mutation and hearing loss in osteogenesis imperfecta patients. Hum. Mutat. 24: 147-154.

Kuivaniemi H, Tromp G and Prockop DJ (1997). Mutations in fibrillar collagens (types I, II, III, and XI), fibril-associated collagen (type IX), and network-forming collagen (type X) cause a spectrum of diseases of bone, cartilage, and blood vessels. Hum. Mutat. 9: 300-315.

Mattick JS (1994). Introns: evolution and function. Curr. Opin. Genet. Dev. 4: 823-831.

Morello R, Bertin TK, Chen Y, Hicks J, et al. (2006). CRTAP is required for prolyl 3-hydroxylation and mutations cause recessive osteogenesis imperfecta. Cell 127: 291-304.

Pace JM, Chitayat D, Atkinson M, Wilcox WR, et al. (2002). A single amino acid substitution (D1441Y) in the carboxylterminal propeptide of the proalpha1(I) chain of type I collagen results in a lethal variant of osteogenesis imperfecta with features of dense bone diseases. J. Med. Genet. 39: 23-29.

Pepin M, Atkinson M, Starman BJ and Byers PH (1997). Strategies and outcomes of prenatal diagnosis for osteogenesis imperfecta: a review of biochemical and molecular studies completed in 129 pregnancies. Prenat. Diagn. 17: 559570.

Pollitt R, McMahon R, Nunn J, Bamford R, et al. (2006). Mutation analysis of COL1A1 and COL1A2 in patients diagnosed with osteogenesis imperfecta type I-IV. Hum. Mutat. 27: 716.

Sykes B (1993). Linkage analysis in dominantly inherited osteogenesis imperfecta. Am. J. Med. Genet. 45: 212-216.

Venturi G, Tedeschi E, Mottes M, Valli M, et al. (2006). Osteogenesis imperfecta: clinical, biochemical and molecular findings. Clin. Genet. 70: 131-139.

Vuorio E and de Crombrugghe B (1990). The family of collagen genes. Annu. Rev. Biochem. 59: 837-872. 